\title{
Combining ability, heterosis, genetic distance and their intercorrelations for waterlogging tolerance traits in chrysanthemum
}

\author{
Jiangshuo Su $\cdot$ Fei Zhang $\cdot$ Xincheng Yang $\cdot$ Yixuan Feng $\cdot$ \\ Xiaodong Yang $\cdot$ Yangyang Wu $\cdot$ Zhiyong Guan $\cdot$ Weimin Fang $•$ \\ Fadi Chen
}

Received: 29 August 2016/Accepted: 5 January 2017/Published online: 20 January 2017

(C) The Author(s) 2017. This article is published with open access at Springerlink.com

\begin{abstract}
Waterlogging tolerance (WT) is a major objective in chrysanthemum breeding programs, and although certain genotypes with different tolerance levels have been identified, their value as parents for WT breeding is unknown. Here, twelve $F_{1}$ crosses derived from an incomplete diallel mating scheme were conducted to investigate combining ability and heterosis for WT and their relationships with parental genetic distance. The results showed that the membership function value of waterlogging (MFVW) was controlled by additive and non-additive gene effects, whereas other growth and biomass traits were mainly controlled by non-additive gene effects. The estimated broad and narrow sense heritabilities of the MFVW were 97.5 and $51.5 \%$, respectively. Combining ability analyses indicated that 'Nannong Xuefeng' showing the largest general combining ability (GCA) effect for the MFVW was the best combiner, and identified several best cross combinations with high positive specific combining ability (SCA) effects for most WT-related traits. Mid- and
\end{abstract}

Electronic supplementary material The online version of this article (doi:10.1007/s10681-017-1837-0) contains supplementary material, which is available to authorized users.

J. Su $\cdot$ F. Zhang $\cdot$ X. Yang $\cdot$ Y. Feng $\cdot$ X. Yang .

Y. Wu · Z. Guan · W. Fang · F. Chen $(\bowtie)$

College of Horticulture, Nanjing Agricultural University,

Weigang No. 1, Nanjing 210095, Jiangsu, People's

Republic of China

e-mail: chenfd@njau.edu.cn high-parent heterosis occurred widely. The three distance measures, based on phenotypic traits (PD), molecular markers (GD) and markers linked with quantitative trait loci (QTL-GD), presented a nonsignificant correlation with combining ability except for the GD with GCA for the relative root fresh weight. The correlations between the QTL-GD and heterosis were significant for certain traits and generally higher than that of the PD or GD and heterosis. The SCA effects were positively correlated with heterosis for most of the WT traits $(0.51 \leq r \leq 0.80)$. The findings benefit understanding the inheritance mode and then achieving desirable improvement for WT in chrysanthemum.

Keywords Chrysanthemum - Combining ability · Flooding tolerance $\cdot$ Heterosis $\cdot$ Inheritance mode

\section{Introduction}

Chrysanthemum (Chrysanthemum morifolium Ramat.) is a traditionally important flower in China and ranks in the top four cut-flower industries worldwide (Zhang et al. 2011; Teixeira da Silva et al. 2013). Chrysanthemum is highly heterozygous and self-incompatible, and usually regarded as a natural hybrid arising from multiple Chrysanthemum species (Chen et al. 1996; Dai et al. 1998; Anderson 2007); as a result, it is often vegetatively propagated. Despite the advent of molecular breeding designs in chrysanthemum, conventional crossbreeding 
between parental cultivars with contrasting target traits is the most effective breeding method, in which excellent $F_{1}$ hybrids with traits of interest will be selected and vegetatively cultivated into a cultivar. Waterlogging stress is a main abiotic constraint that limits chrysanthemum productivity (Yin et al. 2009a, b). Chrysanthemum is usually cropped in South China during summer, which is a season that experiences heavy rainfall and frequent soil waterlogging. In such environments, it is important to produce cultivars that express an acceptable level of waterlogging tolerance (WT).

Understanding the gene action of the targeted traits and selecting suitable parents are two important strategies for achieving desired genetic improvements for chry santhemum. Combining ability is an important parameter that reflects the breeding value of cultivars and includes general combining ability (GCA) and specific combining ability (SCA), which are usually evaluated based on a series of crosses. Diallel or factorial (line $\times$ tester) crossing is most frequently employed (Ahuja and Dhayal 2007). An incomplete diallel cross design can significantly reduce the number of crosses relative to that of a diallel analysis, which requires less effort and has been applied in many crops. In chrysanthemum, Zhang et al. (2010) conducted a $3 \times 4 \mathrm{NCII}$ design to explore the combining ability and genetic parameters for certain horticultural traits and revealed that plant height and leaf length are principally controlled by non-additive genes. However, previous studies were considerably restricted to agronomic and yield traits rather than tolerance or resistance traits.

The heterosis effect has been used in breeding both open-pollinated and self-pollinated plants, such as maize (Suwarno et al. 2014), tomato (Jindal 2016) and wheat (Boeven et al. 2016). In chrysanthemum, heterosis has been widely observed for a few horticultural and resistance traits (Zhang et al. 2011, 2013; Wang et al. 2014). Nevertheless, chrysanthemum is hypothesized to be allohexaploid $(2 \mathrm{n}=$ $6 \mathrm{x}=54$ ), and the species exhibits a complex genetic background that which increasing the difficulty of studying the genetic mechanisms underlying quantitative characteristics. Moreover, identifying beneficial behaviors in progenies via field trials is a timeconsuming and costly process. Thus, the ability to accurately predict superior hybrids prior to field evaluations will enhance the efficiency of breeding activities.
The extent of pair-wise parental genetic distances has been considered a predictor of hybrid performance and heterosis (Marsan et al. 1998). Different methods have been used to evaluate the level of genetic distance, including morphological markers, isozymes and molecular techniques (Weeden and Wendel 1989; Ferriol et al. 2003; Smýkal et al. 2008). Significant time and effort are required to obtain morphological markers, which are frequently influenced by environmental factors. Various molecular markers are currently used for estimating genetic distance, and the SRAP, SSR and SCoT markers have been reported as markers for the genetic diversity and QTL mapping of chrysanthemum (Li et al. 2013, 2016; Zhang et al. 2013). Recently, QTL-linked marker-based GDs (QTL-GDs) have been reported to facilitate effective predictions of heterosis (Wegary et al. 2013). In our earlier study, evaluation of WT in a collection of one hundred chrysanthemum cultivars under three conditions resulted in some genotypes with contrast waterlogging tolerance that could be used as potential donors for future improvement of WT, and some 80 markers $(P \leq 0.05)$ associated with WT have been identified using association mapping ( $\mathrm{Su}$ et al. 2016). Therefore, we attempted to estimate the pair-wise parental genetic distance with the WT-associated markers (equivalent to QTL-GD).

Previous attempts to analyze the relationship among heterosis, GD and combining ability have resulted in different conclusions for various crop species. Betrán et al. (2003) reported a highly significant correlation between GD and SCA effects $(r=0.8)$ in maize under stress and non-stress conditions. Devi and Singh (2011) demonstrated that SCA could emerge as an important factor in the determination of heterosis and per se performance of the hybrids. However, Ceballos et al. (2016) observed weak associations between the GD and SCA effects, which presented $r^{2}$ values ranging from 0.00 to 0.28 . Ndhlela et al. (2015) and Dreisigacker et al. (2005) found no explicit correlation between GD and heterosis. Cress (1966) proposed that the extent of GD between parents is necessary for significant heterosis but is not sufficient to guarantee it. Betrán et al. (2003) suggested that heterosis can be better predicted only when GD is smaller than a certain threshold. Moreover, studies have suggested that the correlation is dependent on the investigated germplasm and GD calculation methods (Melchinger et al. 1990; Tams et al. 2006). 
Thus, little information is available on the heterosis, combining ability and parental genetic diversity and their intercorrelations for WT-related traits in chrysanthemum. The objectives of the present study were to (i) estimate the combining ability, heritability and heterosis of WT, (ii) assess the genetic distance of parents based on morphological and molecular markers and (iii) determine the correlations among combining ability, heterosis and genetic distance. The findings of the present research will provide an indepth understanding of the inheritance pattern of WT in chrysanthemum and facilitate future improvements of chrysanthemum's WT.

\section{Materials and methods}

Parental selection and hybridization

In 2014, seven spray-cut chrysanthemum cultivars of different origins (Table 1) were selected according to an earlier greenhouse-based waterlogging evaluation trial (Su et al. 2016). During flowering, the four waterlogging tolerant genotypes (as female parents) and three waterlogging susceptible genotypes (as male parents) were crossed in a $4 \times 3$ incomplete diallel design (NCII) at the Chrysanthemum Germplasm Resource Preserving Centre (Nanjing Agricultural University, China), and they produced 12 cross combinations. The male parents were strictly bagged, and the female parents were also bagged immediately after hand pollination to prevent access by insects during the crossing process. Mature and plump seeds

Table 1 Origin and waterlogging tolerance (WT) grades of the parental genotypes

\begin{tabular}{llllll}
\hline Parents & & & Origin & MFVW & Grades \\
\hline Female & P1 & Xiaoli & Japan & 0.83 & I \\
& P2 & Winter White & Japan & 0.94 & I \\
& P3 & Qx097 & Unknown & 0.86 & I \\
& P4 & Nannong & China & 0.91 & I \\
Male & P5 & Monalisa & Europe & 0.18 & V \\
& P6 & Qx096 & Unknown & 0.49 & III \\
& P7 & Qx098 & Unknown & 0.39 & IV \\
\hline
\end{tabular}

I, III, IV and V indicate highly tolerant, moderately tolerant, susceptible and highly susceptible, respectively were maintained at room temperature after collecting and then air dried in January 2015.

At the end of March 2015, $\leq 400$ seeds per cross were sown and grown in Styrofoam nursery trays containing field soil under greenhouse conditions. The seedlings were transplanted to the field after $60 \mathrm{~d}$ of germination with a row spacing of $0.3 \mathrm{~m}$ and plant spacing of $0.2 \mathrm{~m}$. Each line was randomly named according to the cross name + Arabic numerals starting from one. Additionally, the four parents were planted in the same screen house. To produce enough cuttings for replicated WT screening, the seedlings were pinched twice.

Waterlogging treatment and field measurements

From August 2015 to October 2015, the seven parents and $F_{1}$ progenies of the 12 crosses were evaluated for WT in a greenhouse experiment. The trial was performed in a randomized complete block with three replicates for the waterlogging treatment and the no waterlogging treatment. First, strong and uniform $6 \mathrm{~cm}$-long cuttings were obtained from each line, and their parents were inserted in Styrofoam nursery trays with 72 caves containing a 1:1 mixture of sterile perlite and vermiculite and then transplanted in disposable plastic pots filled with a 3:1:1 mixture of garden soil, perlite and vermiculite until the cutting seedlings rooted. The pots intended for the waterlogging treatment were transferred in $45 \mathrm{~L}$ plastic bins until the seedlings had 10-12 nodes. The waterlogging stress was imposed by injecting running water into each bin to $3 \mathrm{~cm}$ above the soil surface. Furthermore, additional water was added daily to maintain the water level, whereas the corresponding parents and $F_{1}$ progenies, irrigated every other day to ensure normal growth, were used as control plants.

The stress treatments began on October 2, and at the 4th day of treatment, the leaf wilting index was recorded using a symptom severity scale ranging from 1 to 5, with one representing the least amount of wilt. At the 10th day, the male parents showed severe waterlogging injury symptoms, and the percentage of the dead leaf area was recorded and the different degrees of damage to the leaf and stem were scored following the grading standards established by Yin et al. (2009b). The three traits were only recorded for the plants under stress because the plants in the no stress conditions did not show leaf or stem chlorosis. 
Additionally, the relative shoot height ( $\mathrm{RSH})$, relative root length (RRL), relative shoot fresh weight (RSFW), relative root fresh weight (RRFW), relative shoot dry weight (RSDW) and relative root dry weight (RRDW) were calculated as the ratio of the treatment plant data to the control plant data. The root data were recorded after carefully washing the soil from the roots. The shoots and roots were dried in a forced air oven for more than $72 \mathrm{~h}$ at $105{ }^{\circ} \mathrm{C}$ until reaching a constant weight. During the growing and treating periods in the greenhouse, the average air temperature was $20.1{ }^{\circ} \mathrm{C}$, the humidity was $77.9 \%$, and the lighting time was $16 \mathrm{~h}$.

\section{Statistical analysis}

An analysis of variance (ANOVA) for the recorded traits, combining ability and diallel analysis was conducted using DPS v 7.05 (Tang and Feng 2002). The GCA and SCA effects and genetic parameters were estimated following Model I and Method II of Griffing's method (Griffing 1956). The $\delta_{\mathrm{GCA}}^{2}: \delta_{\mathrm{SCA}}^{2}$ ratio was used to indicate the relative importance of the additive or non-additive genes controlling the evaluated characteristic. Mid-parent heterosis (MPH) and high-parent heterosis (HPH) were calculated as follows: $\mathrm{MPH}=\left[\mathrm{X}_{\mathrm{F} 1}-\left(\mathrm{X}_{\mathrm{P} 1}+\mathrm{X}_{\mathrm{P} 2}\right) / 2\right] /\left[\left(\mathrm{X}_{\mathrm{P} 1}+-\right.\right.$ $\left.\mathrm{X}_{\mathrm{P} 2}\right) / 2$ ]; and $\mathrm{HPH}=\left(\mathrm{X}_{\mathrm{F} 1}-\mathrm{X}_{\mathrm{H}}\right) / \mathrm{X}_{\mathrm{H}}$, where, $\mathrm{X}_{\mathrm{F} 1}$ is the mean performance of the $\mathrm{F}_{1}$ progenies for each cross, $\mathrm{X}_{\mathrm{P} 1}$ is the mean performance of parent one, $\mathrm{X}_{\mathrm{P} 2}$ is the mean performance of parent two and $X_{H}$ is the mean value of the highest performing parent. The analysis of genetic distance among the seven parents was estimated using morphological and molecular markers. The Euclidean distance was calculated from the seven traits using SPSS 20.0 software (http://www- 01.ibm.com), and it was treated as a measure of multivariate phenotypic distance (PD). Nei's (1972) genetic distance was calculated based on 707 informative markers $(371,49$, and 406 generated from 39 SRAP, 7 SCoT and 31 EST-SSR, respectively) as reported by $\mathrm{Li}$ et al. (2016) (GD) and 80 markers significantly associated with WT (QTL-GD) $(P \leq 0.05$, Table S1 and S2) according to a mixed linear model from a previous association mapping study (Su et al. 2016). The dendrograms were constructed from the three distance matrixes using the unweighted pair group method with the arithmetic averages (UPGMA) method of cluster analysis in NTSYS-pc v2.1 software (Rohlf 1998). The relationships among the genetic distance, heterosis and combining ability were assessed by Pearson's correlation coefficients $(r)$ and tested at $P=0.05$ and 0.01 .

\section{Results}

\section{ANOVA and hybrid performance for WT}

ANOVA revealed highly significant $(P<0.01)$ differences among the 12 cross combinations (Table 2), thus indicating the true presence of inherent variation among the crosses, which could also been seen from $C V \%$ for each cross (Table S3). The mean performance of seven parents and $12 \mathrm{~F}_{1}$ crosses is listed in Table 3. The highest $C V \%$ (average of all crosses) was observed for the RRFW (73.9), whereas the lowest was observed (5.6) for the RSH, and the average was 28.8. Phenotype of seven parents on the tenth day of flooding was presented in Fig. 1. P5 showed the highest susceptible response to WT, with a MFVW value of 0.11 , whereas P1 developed the highest

Table 2 Analysis of variance (ANOVA) for the seven WT traits

\begin{tabular}{lrlllllll}
\hline Source & Df & \multicolumn{2}{l}{ Mean squares } & & & \\
\cline { 2 - 8 } & & MFVW & RSH & RRL & RSFW & RRFW & RSDW & RRDW \\
\hline Blocks & 2 & 0.0003 & 0.0006 & 0.0000 & 0.0008 & 0.0001 & 0.0019 & 0.0001 \\
Combination & 11 & $0.0239^{* *}$ & $0.0048^{* *}$ & $0.0532^{* *}$ & $0.0544^{* *}$ & $0.0644^{* *}$ & $0.0113^{* *}$ & $0.0112^{* *}$ \\
Female & 3 & $0.0549^{*}$ & 0.0020 & 0.0864 & 0.0263 & 0.0384 & 0.0162 & 0.0071 \\
Male & 2 & 0.0111 & 0.0060 & 0.0019 & 0.0024 & 0.0222 & 0.0127 & 0.0154 \\
Female & 6 & $0.0128^{* *}$ & $0.0058^{* *}$ & $0.0536^{* *}$ & $0.0857^{* *}$ & $0.0914^{* *}$ & $0.0084^{* *}$ & $0.0119^{* *}$ \\
Error & 22 & 0.0002 & 0.0004 & 0.0002 & 0.0011 & 0.0003 & 0.0016 & 0.0003 \\
\hline
\end{tabular}

*, ** Significance at $P<0.05$ and $P<0.01$, respectively 
Table 3 Mean performance of the parents and $F_{1}$ progenies for the seven WT traits
$L S D_{0.05}, L S D_{0.01}$ : significance difference at $P<0.05$ and $P<0.01$, respectively; $C V / \%$ : percent coefficient of variation

\begin{tabular}{|c|c|c|c|c|c|c|c|}
\hline Parental crosses & MFVW & $\mathrm{RSH}$ & RRL & RSFW & RRFW & RSDW & RRDW \\
\hline \multicolumn{8}{|l|}{ Parents } \\
\hline $\mathrm{P} 1$ & 1.00 & 0.73 & 0.81 & 0.44 & 0.18 & 0.47 & 0.23 \\
\hline $\mathrm{P} 2$ & 0.94 & 0.88 & 0.72 & 0.50 & 0.20 & 0.50 & 0.27 \\
\hline P3 & 0.88 & 0.89 & 0.81 & 0.62 & 0.16 & 0.56 & 0.26 \\
\hline $\mathrm{P} 4$ & 0.86 & 0.87 & 0.68 & 0.49 & 0.14 & 0.48 & 0.19 \\
\hline P5 & 0.11 & 0.77 & 0.69 & 0.39 & 0.05 & 0.44 & 0.11 \\
\hline P6 & 0.35 & 0.81 & 0.57 & 0.53 & 0.06 & 0.47 & 0.12 \\
\hline $\mathrm{P} 7$ & 0.40 & 0.82 & 0.65 & 0.68 & 0.24 & 0.58 & 0.26 \\
\hline \multicolumn{8}{|l|}{$\mathrm{F}_{1}$ crosses } \\
\hline G1 P1 $\times$ P5 & 0.56 & 0.81 & 0.59 & 0.55 & 0.11 & 0.65 & 0.18 \\
\hline $\mathrm{G} 2 \mathrm{P} 2 \times \mathrm{P} 5$ & 0.58 & 0.80 & 0.59 & 0.47 & 0.10 & 0.65 & 0.25 \\
\hline G3 P3 $\times$ P5 & 0.44 & 0.76 & 0.60 & 0.62 & 0.12 & 0.58 & 0.16 \\
\hline G4 P4 × P5 & 0.49 & 0.86 & 0.90 & 0.84 & 0.54 & 0.66 & 0.34 \\
\hline G5 P1 × P6 & 0.56 & 0.83 & 0.60 & 0.54 & 0.08 & 0.58 & 0.13 \\
\hline G6 P2 × P6 & 0.64 & 0.85 & 0.46 & 0.58 & 0.13 & 0.78 & 0.21 \\
\hline G7 P3 × P6 & 0.53 & 0.83 & 0.86 & 0.70 & 0.20 & 0.68 & 0.24 \\
\hline G8 P4 × P6 & 0.53 & 0.89 & 0.67 & 0.68 & 0.13 & 0.64 & 0.16 \\
\hline G9 P1 × P7 & 0.60 & 0.78 & 0.80 & 0.87 & 0.42 & 0.72 & 0.27 \\
\hline $\mathrm{G} 10 \mathrm{P} 2 \times \mathrm{P} 7$ & 0.69 & 0.84 & 0.50 & 0.56 & 0.08 & 0.76 & 0.20 \\
\hline G11 P3 × P7 & 0.37 & 0.85 & 0.66 & 0.51 & 0.13 & 0.66 & 0.27 \\
\hline $\mathrm{G} 12 \mathrm{P} 4 \times \mathrm{P} 7$ & 0.64 & 0.77 & 0.66 & 0.45 & 0.09 & 0.66 & 0.28 \\
\hline Mean $_{\text {Parents }}$ & 0.65 & 0.83 & 0.70 & 0.52 & 0.15 & 0.50 & 0.21 \\
\hline $\operatorname{Mean}_{F 1}$ & 0.55 & 0.82 & 0.66 & 0.61 & 0.18 & 0.67 & 0.22 \\
\hline Mean $_{\text {Total }}$ & 0.59 & 0.82 & 0.68 & 0.58 & 0.17 & 0.61 & 0.22 \\
\hline$L S D_{0.05}$ & 0.09 & 0.13 & 0.13 & 0.17 & 0.05 & 0.16 & 0.05 \\
\hline$L S D_{0.01}$ & 0.12 & 0.17 & 0.17 & 0.22 & 0.07 & 0.21 & 0.07 \\
\hline $\mathrm{CV} / \%$ & 37.43 & 5.6 & 17.53 & 22.21 & 73.89 & 16.67 & 28.47 \\
\hline
\end{tabular}

MFVW value of 1.00 followed by P2 (0.94), P3 (0.88), P4 (0.86), P7 (0.40) and P6 (0.35) in descending order. The MFVW values of $F_{1}$ crosses ranged from 0.37 (G11) to 0.69 (G10) and averaged 0.55. Parents P2, P3 and $\mathrm{P} 7$ showed good performances for most of the WT-related traits. P5 expressed the lowest mean values for most of the traits with the exception of the RSH and RRL. Progenies from G8, G4, G6 and G11 had the highest RSH (0.85-0.89). Progenies from G4, G7 and G9 always had the top 3 scores for the RRL, RSFW and RRFW. G6, G10 and G9 yielded the highest values of the RSDW (0.72-0.78), whereas G4, G12, G9 and G11showed good performance for the RRDW (0.27-0.34). Overall, the progenies from crosses involving $\mathrm{P} 4$ performed better for the studied traits. Moreover, root severity (RRH, RRFW and RRDW) was higher than shoot severity (RSH, RSFW and RSDW), indicating that root injury is a major cause of waterlogging stress. The overall mean performance of the parental genotypes exceeded that of the crosses for the MFVW, RSH and RRL.

Combining ability performance

The variance analysis of combining ability indicated that the SCA effects were significant $(P<0.01)$ for all of the analyzed traits, and significant differences $(P<0.05)$ were only detected for the GCA effects for the MFVW in females (Table 2).

Higher MFVWs indicated a higher WT resistance and a desirably high GCA for WT. The order of GCA effects for the MFVW of the parents (from highest to lowest) was P2 $>$ P7 $>$ P1 $>$ P6 $>$ P4 $>$ P5 $>$ P3 (Table 4), and four parents had positive GCA effects. P2 was a waterlogging tolerant parent and had the largest GCA value for the MFVW and RSDW, 

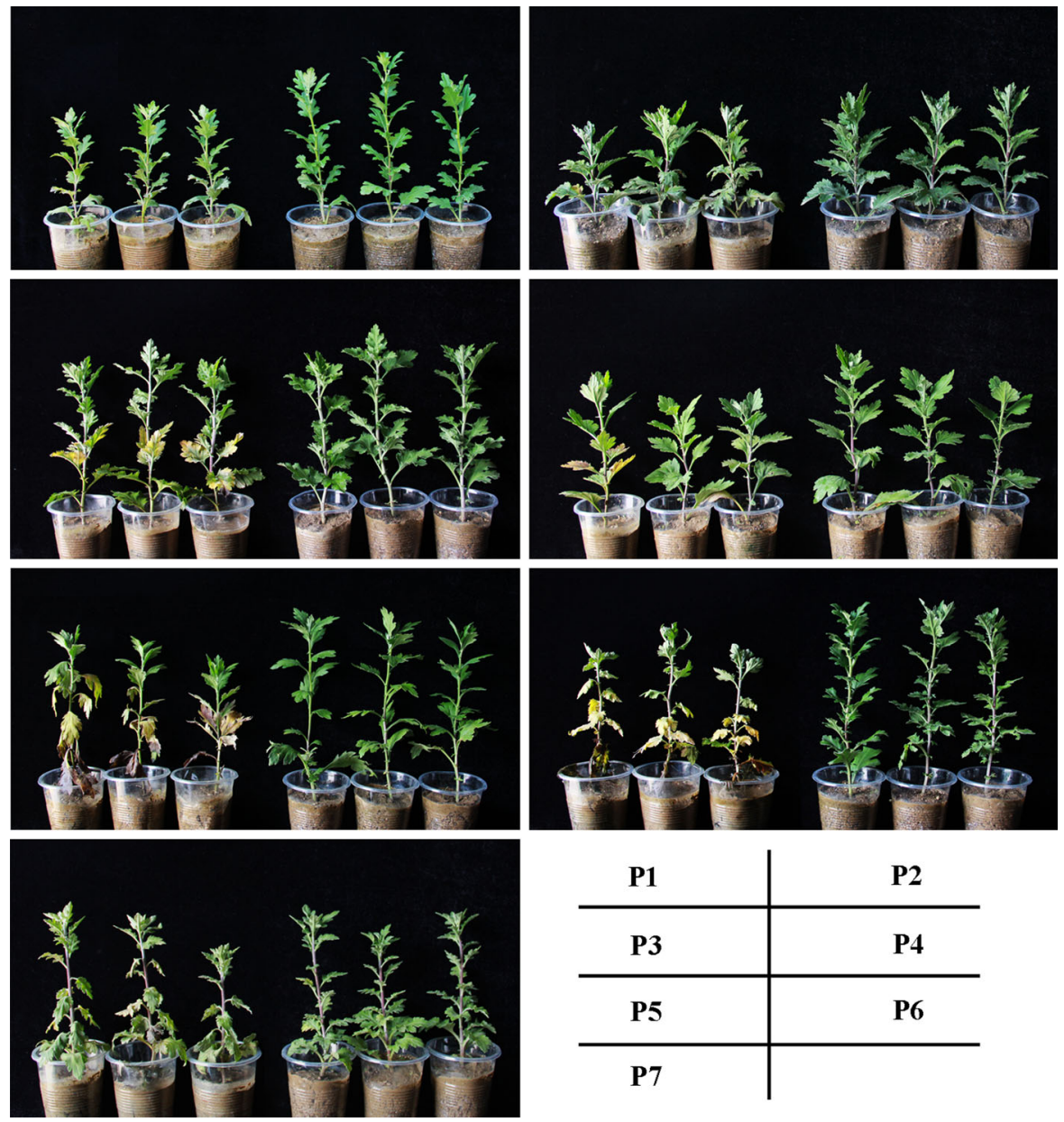

\begin{tabular}{c|c} 
P1 & P2 \\
\hline P3 & P4 \\
\hline P5 & P6 \\
\hline P7 &
\end{tabular}

Fig. 1 Phenotype of seven parents on the tenth day of flooding (the three on the left are flooded plants and the three on the right are nonstressed plants)

whereas it had the lowest GCA for the RRL, RSFW and RRFW. A relatively higher positive GCA effect for the RRL, RRFW and RRDW was notably observed in the waterlogging sensitive cultivar P5, which indicated that P5 had the ability to maintain better root structure under waterlogging stress. P4 was recognized as the best material for WT breeding because it demonstrated the highest positive GCA effects for most of the measured traits with the exception of the RSDW. Conversely, the P3 and P6 exhibited the lowest negative GCA effects for the majority of traits.

Positive SCA effects for the MFVW were detected in half of the 12 crosses, of which G7, G12 and G10 ranked in the top three. In contrast, G11, G8 and G4 showed the highest negative SCA effects for the
MFVW. For the RRFW, the largest SCA effect was found in G4 (137.29) and the lowest was found in G12 (-92.51). For 4 of the 6 WT-related traits, negative SCA effects occurred in $\geq 50 \%$ of the overall crosses. The SCA effects of the RSH ranged from -7.37 (G12) to 6.29 (G11) and of the RRL ranged from (-17.53) to G7 (24.28). Taking all traits into consideration, G4, G7 and G9 appeared to be the best cross combinations because six out of seven traits expressed high positive SCA effects. Conversely, although the hybrid combination G12 ranked second for the MFVW, it exhibited negative SCA effects for all other traits and was similar to G3 except for the low positive SCA for the RSFW. Additionally, G5 (P1 and P6) showed negative SCA effects for all traits; thus, obtaining WT hybrids is not likely. 
Table 4 Estimates of the relative GCA and SCA effects for parents and crosses on the seven WT traits

\begin{tabular}{|c|c|c|c|c|c|c|c|}
\hline Parental crosses & MFVW & $\mathrm{RSH}$ & RRL & RSFW & RRFW & RSDW & RRDW \\
\hline \multicolumn{8}{|c|}{ GCA effects for parents } \\
\hline P1 & 3.87 & -1.96 & 0.51 & 6.51 & 14.82 & -3.03 & -13.54 \\
\hline P2 & 15.12 & 0.88 & -20.95 & -12.12 & -41.34 & 9.41 & -2.11 \\
\hline P3 & -18.83 & -1.01 & 7.26 & -0.90 & -16.38 & -4.19 & -1.12 \\
\hline P4 & -0.15 & 2.10 & 13.18 & 6.51 & 42.90 & -2.20 & 16.77 \\
\hline P5 & -6.28 & -1.72 & 1.98 & 0.90 & 23.09 & -4.89 & 3.98 \\
\hline P6 & 2.31 & 3.14 & -1.82 & 1.72 & -25.12 & 0.08 & -17.64 \\
\hline P7 & 3.97 & -1.42 & -0.17 & -2.62 & 2.03 & 4.81 & 13.66 \\
\hline \multicolumn{8}{|c|}{ SCA effects for crosses } \\
\hline G1 P1 × P5 & 4.27 & 2.27 & -13.30 & -17.90 & -74.26 & 4.89 & -12.92 \\
\hline $\mathrm{G} 2 \mathrm{P} 2 \times \mathrm{P} 5$ & -3.97 & -1.79 & 9.16 & -11.75 & -23.71 & -7.05 & 9.94 \\
\hline G3 P3 $\times$ P5 & 4.67 & -5.17 & -17.53 & 0.36 & -39.31 & -3.90 & -29.81 \\
\hline G4 P4 × P5 & -4.97 & 4.70 & 21.66 & 29.29 & 137.29 & 6.05 & 32.80 \\
\hline G5 P1 × P6 & -4.92 & -0.57 & -7.98 & -19.80 & -44.77 & -10.53 & -9.19 \\
\hline $\mathrm{G} 6 \mathrm{P} 2 \times \mathrm{P} 6$ & -2.31 & -0.98 & -6.80 & 4.79 & 37.60 & 7.38 & 12.17 \\
\hline G7 P3 $\times$ P6 & 13.56 & -1.12 & 24.28 & 12.57 & 51.95 & 5.55 & 23.11 \\
\hline G8 P4 × P6 & -6.33 & 2.67 & -9.50 & 2.44 & -44.77 & -2.40 & -26.09 \\
\hline G9 P1 $\times$ P7 & 0.65 & -1.69 & 21.28 & 37.70 & 119.03 & 5.64 & 22.11 \\
\hline $\mathrm{G} 10 \mathrm{P} 2 \times \mathrm{P} 7$ & 6.28 & 2.77 & -2.36 & 6.96 & -13.88 & -0.33 & -22.11 \\
\hline G11 P3 × P7 & -18.23 & 6.29 & -6.76 & -12.93 & -12.64 & -1.66 & 6.71 \\
\hline G12 P4 $\times$ P7 & 11.30 & -7.37 & -12.16 & -31.74 & -92.51 & -3.65 & -6.71 \\
\hline
\end{tabular}

Estimation of genetic parameters

All of the GCA/SCA ratios were lower than 1.0 except for the MFVW (1.1), and the RSH, RSFW and RRFW presented ratios of 0 (Table 5). As the integrated indicator of WT, the MFVW showed high broad sense heritability $(97.5 \%)$ as well as the highest narrow sense heritability $(51.5 \%)$, which reinforced that the MFVW was controlled by both additive and non-additive genes, with the former showing predominance. The other six WT traits had high broad sense heritability but low narrow sense heritability, and the narrow sense heritability for the RSFW and RRFW traits were zero, which suggests that non-additive gene action was primarily or completely responsible for their inheritance.

\section{Heterosis}

The heterosis (MPH and $\mathrm{HPH}$ ) of the $\mathrm{F}_{1}$ hybrids varied in magnitude (Table 6). Generally, the mean $\mathrm{HPH}$ values were lower than the MPH values for all traits, and approximately 59.5 and $38.1 \%$ of the crosses showed positive MPH and HPH, respectively. For the MFVW, five out of 12 crosses expressed positive MPH, whereas all the hybrids showed negative HPH. The MPH values ranged from $-42.1 \%$ for G11 to $10.2 \%$ for $\mathrm{G} 2$, whereas the HPH values varied from $-57.6 \%$ for G11 to $-26.1 \%$ for $\mathrm{G} 10$ and G12. Considering all the traits, G4 displayed the highest positive MPH (482.3\%) and HPH (286.6\%) and G10 had the highest negative MPH $(-63.0 \%)$ and HPH $(-66.2 \%)$ for the RRFW. The RSH and RRL showed similar MPH and HPH trends. All of the hybrids exhibited positive MPH and HPH for the RSDW; the highest MPH (61.8\%) and HPH (55.9\%) were observed in G6, whereas the lowest MPH (16.0\%) and HPH (3.6\%) were observed in G3. For the RSFW, most of heterosis effects were positive, and the highest MPH (91.2\%) and HPH (72.8\%) were observed in G4. For the RRDW, 75 and $33.3 \%$ of crosses showed positive MPH and HPH, respectively, of which G4 had the best MPH (126.8\%) and HPH $(79.3 \%)$ and G5 had the lowest MPH $(-25.3 \%)$ and HPH (-42.1\%). 


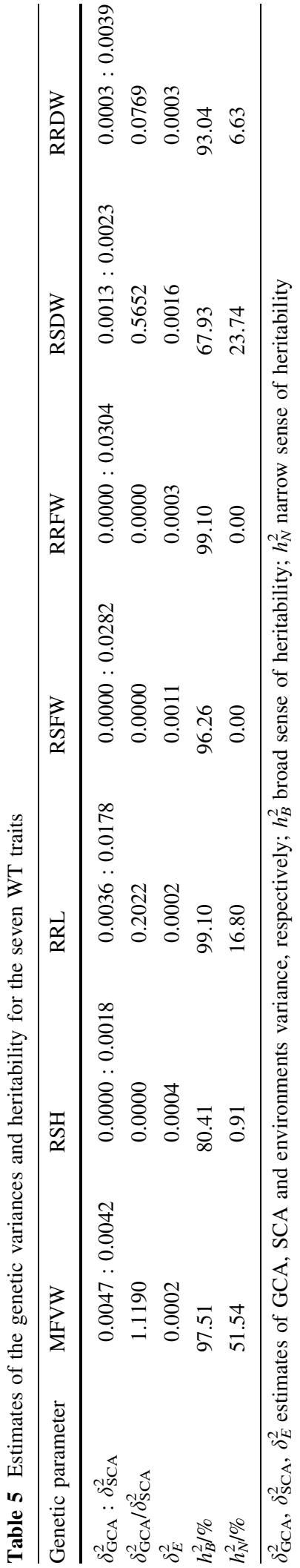

Parental genetic distance

The PD ranged from 0.51 for G11 to 0.92 for G1 with a mean of 0.69 , whereas the GD ranged from 0.35 (G10) to 0.59 (G4) and the QTL-GD ranged from 0.25 (G10) to 0.85 (G4), with similar mean values of 0.47 and 0.49 , respectively. Of the male parents, $\mathrm{P} 5$ had the largest PD (0.85), GD (0.54) and QTL-GD (0.60) with the four female parents. Male P7 showed the lowest PD (0.57) and QTL-GD (0.37) and male P6 showed the lowest GD (0.42) with the 4 female parents. Of the female parents, P1 showed the largest PD (0.77) and GD (0.51), P2 showed the lowest GD (0.41) and QTLGD (0.41), and P4 showed the largest QTL-GD (0.67) and lowest PD (0.61) with the 3 male parents (Table 7). Additionally, a highly significant correlation was observed for the GD vs. QTL-GD $(P<0.05 ; r=0.63)$ and PD $v s$. GD $(P<0.05$; $r=0.62)$, whereas a low correlation was detected for the PD vs. QTL-GD $(r=0.26)$ (Table S4).

A cluster analysis based on the PD, GD and QTLGD is shown in Fig. 2. The PD dendrogram classified the parents distinctly into a female group (P1, P2, P3 and P4) and a male group (P5, P6 and P7). The female parents P2 and P4 (and male parents P5 and P6) exhibited similar performances for almost all WT traits and thus were closely grouped. For the other two molecular marker-based distance measures (GD and QTL-GD), the dendrograms assigned the parents into three groups that did not correspond to the parental type as in PD-based clustering. In the marker-based dendrograms, the male parent P5 was separated from the others at a dissimilarity distance of approximately 0.52 .

Correlation analysis

The correlation coefficients of the GD/QTL-GD and GCA/SCA effects were generally higher than those between the PD and GCA/SCA effects (Table 8). As for the MFVW, the values of the PD, GD and QTLGD were negatively correlated with combining ability except for the values between the SCA effects and $\mathrm{PD}(r=0.09)$. However, a significant correlation was barely detected between the distance measures and combining ability, and a significant correlation was observed between the GD and GCA for the RRFW $(P<0.05, r=0.86)$.

The three distance measures were correlated positively with MPH but negatively correlated with 
Table 7 Estimates of phenotypic distance (PD) and two genetic distances (GD and QTL-GD) between parents

\begin{tabular}{llllll}
\hline Parents & P1 & P2 & P3 & P4 & Mean \\
\hline P5 & & & & & \\
PD & 0.92 & 0.87 & 0.84 & 0.77 & 0.85 \\
GD & 0.52 & 0.53 & 0.50 & 0.59 & 0.54 \\
QTL-GD & 0.43 & 0.58 & 0.54 & 0.85 & 0.60 \\
P6 & & & & & \\
PD & 0.72 & 0.65 & 0.62 & 0.54 & 0.63 \\
GD & 0.49 & 0.36 & 0.38 & 0.44 & 0.42 \\
QTL-GD & 0.50 & 0.40 & 0.42 & 0.71 & 0.51 \\
P7 & & & & & \\
PD & 0.68 & 0.58 & 0.51 & 0.52 & 0.57 \\
GD & 0.52 & 0.35 & 0.43 & 0.47 & 0.44 \\
QTL-GD & 0.36 & 0.25 & 0.40 & 0.45 & 0.37 \\
Mean & & & & & \\
PD & 0.77 & 0.70 & 0.66 & 0.61 & 0.69 \\
GD & 0.51 & 0.41 & 0.44 & 0.50 & 0.47 \\
QTL-GD & 0.43 & 0.41 & 0.45 & 0.67 & 0.49 \\
\hline
\end{tabular}

HPH for the MFVW, and the highest correlation was shown for the PD and MPH $(r=0.45)$. The PD and GD did not show a significant correlation with MPH and HPH for all of the traits, whereas QTL-GD showed positive and significant correlations with MPH for the RSFW, RRFW and RRDW and with HPH for the RRL, RSFW and RRFW.

For the MFVW, the SCA was significantly correlated with HPH $(P<0.05, r=0.60)$ rather than with MPH $(r=0.52)$. For the other six WT traits, the correlation between the SCA effects and MPH were positive and significant, with values of 0.62 for the RSDW and 0.75 for the RSFW and RRFW. Similarly, a positive and significant correlation was found between the SCA and HPH for all of the WT traits except RSDW, and the coefficient varied, with values of 0.67 for the RRL and 0.80 for the RRFW.

\section{Discussion}

Leaf chlorosis is a direct symptom of flooding that has been successfully applied in wheat (Boru et al. 2001), soybean (Cornelious et al. 2005) and barley (Li et al. 2008). In our study, a MFVW that integrates a wilting index, a chlorosis score and the dead leaf proportion of waterlogged plants was deployed to measure WT. In a 

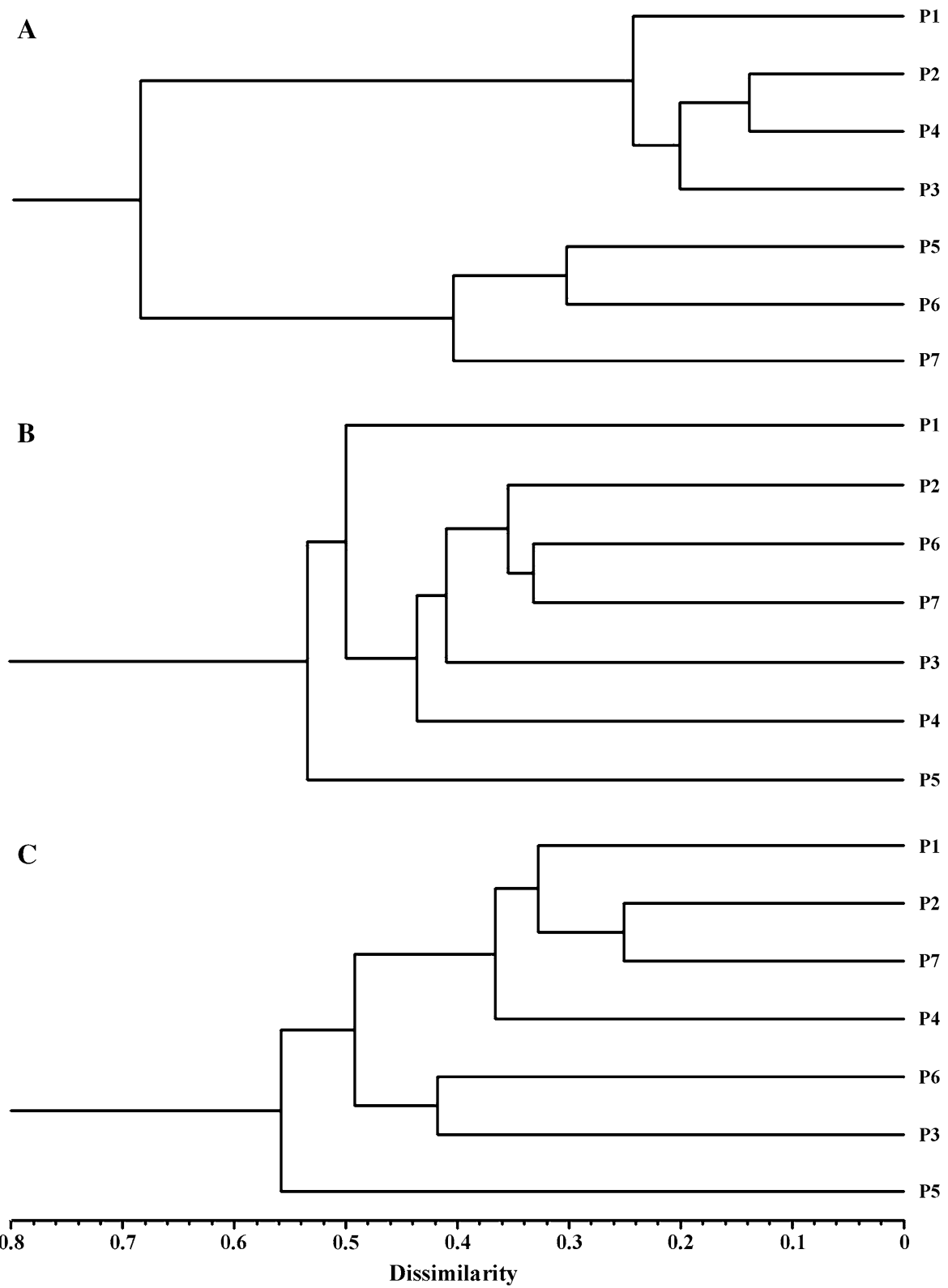

Fig. 2 UPGMA dendrograms of the seven parents constructed based on PD (a), GD (b) and QTL-GD (c)

previous study, this measure was effective for screening WT in 100 chrysanthemum cultivars (Su et al. 2016). We also recorded the relative shoot/root growth and biomass related to WT. The results showed considerable variations among the seven parents and $\mathrm{F}_{1}$ crosses for all WT traits, indicating the possibility of selecting preferred parents and hybrids with high WT. Among the crosses, the lowest MFVW value was observed in G11 while the highest was found in G10.
Both of these crosses involved P7, which exhibited the best WT among the three male parents. Moreover, the mean MFVW value for G11 was even lower than that of P7, whereas the mean MFVW value of the other 11 crosses generally ranged between that of the female and male parents, indicating the complexity of WT inheritance.

Approximately $60.0 \%$ of the crosses showed positive MPH but negative HPH for the WT traits, 
Table 8 Person correlation coefficients among the combining ability, heterosis and parental genetic distance (PD, GD and QTL-GD) for the seven WT traits

\begin{tabular}{|c|c|c|c|c|c|c|c|}
\hline Traits & MFVW & RSH & RRL & RSFW & RRFW & RSDW & RRDW \\
\hline \multicolumn{8}{|l|}{ PD } \\
\hline GCA & -0.10 & -0.49 & -0.16 & 0.07 & 0.16 & -0.39 & -0.31 \\
\hline SCA & 0.09 & -0.11 & 0.03 & 0.02 & 0.02 & 0.00 & 0.02 \\
\hline $\mathrm{MPH}$ & 0.45 & 0.17 & -0.20 & 0.43 & 0.22 & 0.15 & 0.18 \\
\hline $\mathrm{HPH}$ & -0.27 & 0.05 & -0.14 & 0.39 & 0.17 & 0.10 & -0.05 \\
\hline \multicolumn{8}{|l|}{ GD } \\
\hline GCA & -0.27 & -0.44 & 0.53 & 0.66 & $0.86^{*}$ & -0.70 & 0.23 \\
\hline SCA & -0.19 & -0.04 & 0.18 & 0.08 & 0.17 & -0.13 & 0.22 \\
\hline MPH & 0.16 & 0.20 & 0.33 & 0.57 & 0.54 & -0.17 & 0.55 \\
\hline $\mathrm{HPH}$ & -0.38 & 0.08 & 0.45 & 0.49 & 0.53 & -0.15 & 0.49 \\
\hline \multicolumn{8}{|c|}{ QTL-GD } \\
\hline GCA & -0.27 & 0.37 & 0.56 & 0.53 & 0.66 & -0.56 & 0.30 \\
\hline SCA & -0.30 & 0.17 & 0.16 & 0.16 & 0.20 & -0.09 & 0.15 \\
\hline $\mathrm{MPH}$ & 0.16 & 0.28 & 0.53 & $0.60 *$ & $0.69 *$ & 0.02 & $0.69 *$ \\
\hline $\mathrm{HPH}$ & -0.24 & 0.19 & $0.63 *$ & $0.64 *$ & $0.64 *$ & 0.12 & 0.55 \\
\hline \multicolumn{8}{|l|}{ SCA } \\
\hline MPH & 0.52 & $0.69 *$ & $0.71 * *$ & $0.75^{* *}$ & $0.75^{* *}$ & $0.62 *$ & $0.69 *$ \\
\hline $\mathrm{HPH}$ & $0.60^{*}$ & $0.68 *$ & $0.67 *$ & $0.68 *$ & $0.80 * *$ & 0.51 & $0.68^{*}$ \\
\hline
\end{tabular}

*, ** Significance at $P<0.05$ and $P<0.01$, respectively

indicating heterosis in the hybrids. Although the HPH for the MFVW was consistently negative, a number of lines (Table S5) had higher MFVW values than their tolerant female parents, which indicates that improved WT lines can be selected. All or most of the crosses displayed positive MPH and HPH for the RSDW and RSFW, thereby showing that the hybrids had better shoot biomass than their parents. Fairly negative or low positive values of MPH and HPH for the RSH and RRL indicated that the growth traits might be predominantly controlled by recessive effects among the parents.

In chrysanthemum, traditional cross breeding is one of the most effective methods of cultivating improved varieties via the exploitation of heterosis. The magnitude of the genetic distance between parental lines is vital for the utility of heterosis. To provide useful information for predicting WT heterosis in chrysanthemum, we investigated genetic distance using morphological (phenotypic) and molecular markers. The maximum and minimum distances yielded by the GD and QTL-GD among the 12 crosses were consistent and moderately high. Significant correlations were observed between the GD and QTL-GD as well as between the GD and PD, which is inconsistent with the results of Wegary et al. (2013), who found a nonsignificant correlation between morphological distance and GD in maize.

The GCA effect is the average performance of a certain parent over a series of hybrids, and it is associated with additive gene effects, whereas the SCA effect reveals deviations in the performance of a certain cross from the performance predicted by the parents' GCA effects, and it is associated with nonadditive gene effects (Musembi et al. 2015). In the current study, the GCA to SCA variance ratios of the MFVW were approximately equal to 1 and the narrow sense heritability of the MFVW was approximately $51.5 \%$. These results suggest that both additive and non-additive gene effects are responsible for the inheritance of WT in chrysanthemum. Similar results were reported in wheat (Tarekegne 2001) and maize (Zaidi et al. 2010). Zhou et al. (2007) and Yeboah et al. (2008) reported that WT was mainly controlled by additive gene effects, which is inconsistent with the findings of our study. However, the GCA-SCA 
variance ratios and narrow sense heritability of the six WT traits were relatively small, which indicates that non-additive gene effects predominantly control these growth and biomass traits, which is similar to the results reported by Cheng et al. (2010) for Brassica napus L. under waterlogging stress conditions.

We found that the GCA and SCA effects varied between the parents or crosses, and both effects had positive and negative values for all WT traits. Generally, the tolerant parents tended to have positive high values while the susceptible parents had negative or low positive values for the MFVW. For example, P5 is the most sensitive parent and had most negative GCA effect. However, exceptions were observed. For example, although P3 is a tolerant parent with a high MFVW value, it had the highest negative GCA effect. Because the GCA effect is controlled by stable additive gene effects, parents with significant GCA effects are considered to be good combiners and can accelerate breeding programs (Comstock et al. 1949; Dar et al. 2016). As a result, parent $P 4$ showed positive effects for almost all the studied traits and could therefore be regarded as a promising parent in chrysanthemum WT breeding. P1 and P5 were also good general combiners for RRFW. In the current study, P4 and P5 both expressed positive GCA effects for RRL, RSFW, RRFW and RRDW, and their cross combination (G4) had relatively high and positive SCA effects for the four WT traits. However, positive correlations were not observed between GCA and SCA for all crosses. For example, parents P3 and P5 both exhibited negative GCA effects for the MFVW, although the SCA effects for the MFVW of G3 $(\mathrm{P} 3 \times \mathrm{P} 5)$ were positive. Similarly, P2 and P6 had positive GCA effects, although they produced progenies with a negative SCA effect for the MFVW. The inconsistent relationship between GCA and SCA effects has frequently been reported in studies focused on combining abilities (Sincik et al. 2014; Avin et al. 2016) and is indicative of the complexity of quantitative traits. Therefore, breeders should pay attention to both GCA and SCA effects. Overall, the crosses G4, G7 and G9 showed positive SCA effects for six of the seven WT traits; specifically, G7 had the highest SCA effect for the MFVW. Moreover, the above three hybrids also had positive MPH and HPH for most of the studied traits, thus indicating their high value for WT breeding.
Many studies have reported correlations among genetic distance, heterosis and SCA effects, although these studies presented inconsistent and contextspecific conclusions because they used different materials and methods. Heterosis mainly depends on the paired differences of specific genetic loci between both parents. Nevertheless, most previous studies used genome-wide molecular marker data, which lack specificity and accuracy. Tiede et al. (2015) showed that segregating informative genome-wide markers could improve the accuracy of predicting genetic variance across 40 barley parents. Wegary et al. (2013) suggested that the genetic distance calculated using selected markers associated with quantitative trait loci (QTL) may better predict heterosis. The results of the present study showed that the magnitude of correlation coefficients for PD and GD with HPH and MPH for all the studied traits were not significant. However, the QTL-GD values were positively and significantly correlated with MPH for RSFW, RRFW and RRDW and HPH for RRL, RSFW and RRFW (0.60-0.69), thus indicating that previously selected molecular markers associated with WT could be applied in chrysanthemum cross breeding. The results were similar to the findings by Hung et al. (2013), who showed that the QTL-GD values based on 56 SSR markers linked to targeted QTLs were negatively and significantly correlated with heterosis for productive tiller percentage. Although a non-significant correlation was observed for GD and PD with heterosis, GD generally had greater correlation coefficients than PD for all of the traits in this study. Wegary et al. (2013) also reported that morphological distances were less important than molecular marker-based genetic distances for predicting the $\mathrm{F}_{1}$ performance of heterosis and SCA effects for grain traits. Nevertheless, PD was a better predictor of gene variance than GD across a 26 maize bi-parent group for 19 traits (Hung et al. 2012).

Significant correlations were not observed between the distance measures and combining abilities except for GD with GCA for RRFW. However, the distance measures generally showed stronger correlations with the GCA effects than with the SCA effects (absolute coefficients) for almost all traits, and GD and QTL-GD showed relatively high absolute correlation coefficient values $(0.23-0.86)$ with GCA. These results indicate that the three distance measures might not effectively predict SCA effects, although they indicate that GD 
and QTL-GD have a closer relationship with GCA effects in the set of materials used in this study. In contrast, Charcosset and Essioux (1994) illustrated that SCA is a more important than GCA with regards to the correlation with parental GD. Many studies have demonstrated that parental GD has a weak and nonsignificant correlation with SCA effects (Tams et al. 2006; Ceballos et al. 2016). However, Shamsuddin (1985) found a significant correlation between GD and SCA effects for grain yields $(r=0.44, P<0.01)$. ElMaghraby et al. (2005) also reported that GDs based on SSR markers were significantly associated with grain yield and heterosis under drought stress. All of these results suggest that the correlation between genetic distance and SCA is complicated. An important discovery by our study is that SCA effects had a stronger positive correlation with MPH and HPH for all of the traits $(0.51-0.80)$, and most of the correlations were significant, although this result may have occurred because SCA and heterosis are responses to non-additive gene effects.

In conclusion, this is the first report on the heterosis, combining ability and parental genetic distance and their intercorrelations for WT-related traits in chrysanthemum. Findings resulted from this study add a brandnew knowledge to the inheritance mode of WT in chrysanthemum, and will be beneficial for achieving new chrysanthemum with desirable WT. Specifically, it can be predicted that crossbreeding with the identified parents with strong GCA will enable the production of chrysanthemum with improved WT, and the hybrids with extreme WT identified in this study will serve as important breeding materials or be cultivated as new cultivar in the near future.

Acknowledgements This work was financially supported by the Grant from the National Natural Science Foundation of China (Grant Nos.31425022 and 31272196), and Research Funds for the Central Universities (Grant No. KYZC201601).

Author's contributions F.C. and F.Z. conceived and designed the project; F.C., W.F. and Z.G. provided the materials; J.S., X.Y., Y.F., X.Y., and Y.W. conducted experiments; J.S. and F.Z. analyzed the data and wrote the manuscript; and J.S., F.Z. and F.C. revised the manuscript.

\section{Compliance with ethical standards}

Conflict of interest The authors declare that they have no conflict of interest.
Open Access This article is distributed under the terms of the Creative Commons Attribution 4.0 International License (http:// creativecommons.org/licenses/by/4.0/), which permits unrestricted use, distribution, and reproduction in any medium, provided you give appropriate credit to the original author(s) and the source, provide a link to the Creative Commons license, and indicate if changes were made.

\section{References}

Ahuja SL, Dhayal LS (2007) Combining ability estimates for yield and fibre quality traits in $4 \times 13$ line tester crosses of Gossypium hirsutum. Euphytica 153:87-98

Anderson NO (2007) Chrysanthemum (Dendranthema $\times$ grandiflora Tzvelv.). In: Anderson NO (ed) Flower breeding and genetics. Springer, Netherlands, pp 389-437

Avin FA, Bhassu S, Rameeh V, Tan YS, Vikineswary S (2016) Genetics and hybrid breeding of Pleurotus pulmonarius: heterosis, heritability and combining ability. Euphytica 209:85-102

Betrán FJ, Ribaut JM, Beck D, de León DG (2003) Genetic diversity, specific combining ability, and heterosis in tropical maize under stress and nonstress environments. Crop Sci 43:797-806

Boeven PHG, Longin CFH, Würschum T (2016) A unified framework for hybrid breeding and the establishment of heterotic groups in wheat. Theor Appl Genet 129:1231-1245

Boru G, Van Ginkel M, Kronstad WE, Boersma L (2001) Expression and inheritance of tolerance to waterlogging stress in wheat. Euphytica 117:91-98

Ceballos H, López-Lavalle LB, Calle F, Morante N, Ovalle TM, Hershey C (2016) Genetic distance and specific combining ability in cassava. Euphytica 210:79-92

Charcosset A, Essioux L (1994) The effect of population structure on the relationship between heterosis and heterozygosity at marker loci. Theor Appl Genet 89:336-343

Chen FD, Chen PD, Li HJ (1996) Genome analysis and their phylogenetic relationships of several wild species of Dendranthema in China. Acta Hortic Sin 23(1):67-72

Cheng Y, Gu M, Cong Y, Zou C, Zhang X, Wang H (2010) Combining ability and genetic effects of germination traits of Brassica napus L. under waterlogging stress condition. Agr Sci China 9:951-957

Comstock RE, Robinson HF, Harvey PH (1949) A breeding procedure designed to make maximum use of both general and specific combining ability. Agron J 41:360-367

Cornelious B, Chen P, Chen Y, De Leon N, Shannon JG, Wang D (2005) Identification of QTLs underlying water-logging tolerance in soybean. Mol Breed 16:103-112

Cress CE (1966) Heterosis of the hybrid related to gene frequency differences between two populations. Genetics 53:269

Dai SL, Chen JY, Li WB (1998) Application of RAPD analysis in the study on the origin of Chinese cultivated chrysanthemum. Acta Bot Sin 40(11):1053-1059 
Dar ZA, Wani SA, Wani MA (2016) Heterosis and combining ability analysis for seed yield and its attributes in Brassica rapa ssp Brown sarson. J Oilseed Brass 2:21-28

Devi P, Singh NK (2011) Heterosis, molecular diversity, combining ability and their interrelationships in short duration maize (Zea mays L.) across the environments. Euphytica 178:71-81

Dreisigacker S, Melchinger AE, Zhang P, Ammar K, Flachenecker C, Hoisington D, Warburton ML (2005) Hybrid performance and heterosis in spring bread wheat, and their relations to SSR-based genetic distances and coefficients of parentage. Euphytica 144:51-59

El-Maghraby MA, Moussa ME, Hana NS, Agrama HA (2005) Combining ability under drought stress relative to SSR diversity in common wheat. Euphytica 141:301-308

Ferriol M, Picó B, Nuez F (2003) Genetic diversity of a germplasm collection of Cucurbita pepo using SRAP and AFLP markers. Theor Appl Genet 107:271-282

Griffing B (1956) Concept of general and specific combining ability in relation to diallel crossing systems. Aust J Bio Sci 9:463-493

Hung HY, Browne C, Guill K, Coles N, Eller M, Garcia A, Lepak N, Melia-Hancock S, Oropeza-Rosas M, Salvo S, Upadyayula N, Buckler ES, Flint-Garcia S, McMullen MD, Rocheford TR, Holland JB (2012) The relationship between parental genetic or phenotypic divergence and progeny variation in the maize nested association mapping population. Heredity 108:490-499

Hung YX, Liu YZ, Guo JF (2013) Relationship between QTLSSR marker based genetic distance, combining ability, and heterosis of productive tiller percentage in hybrid rice. J Northwest A\&F Univ 41:43-50

Jindal K (2016) Exploiting yield potential in tomato (Solanum lycopersicum L.) through heterosis breeding. Plant Gene Trait 7:1-7

Li H, Vaillancourt R, Mendham N, Zhou M (2008) Comparative mapping of quantitative trait loci associated with waterlogging tolerance in barley (Hordeum vulgare L.). BMC Genom 9:401

Li P, Jiang J, Chen S, Guan Z, Liao Y, Fang W, Chen F (2013) Establishment and optimization of SCoT molecular marker system in chrysanthemum and its application of analysis on genetic diversity. Acta Hortic Sin 40:2015-2025

Li P, Zhang F, Chen S, Jiang J, Wang H, Su J, Fang W, Guan Z, Chen F (2016) Genetic diversity, population structure and association analysis in cut chrysanthemum (Chrysanthemum morifolium Ramat.). Mol Genet Genomics 291:1117-1125

Marsan PA, Castiglioni P, Fusari F, Kuiper M, Motto M (1998) Genetic diversity and its relationship to hybrid performance in maize as revealed by RFLP and AFLP markers. Theor Appl Genet 96:219-227

Melchinger AE, Lee M, Lamkey KR, Woodman WL (1990) Genetic diversity for restriction fragment length polymorphisms: relation to estimated genetic effects in maize inbreds. Crop Sci 30:1033-1040

Musembi KB, Githiri SM, Yencho GC, Sibiya J (2015) Combining ability and heterosis for yield and drought tolerance traits under managed drought stress in sweetpotato. Euphytica 201:423-440
Ndhlela T, Herselman L, Semagn K, Magorokosho C, Mutimaamba C, Labuschagne MT (2015) Relationships between heterosis, genetic distances and specific combining ability among CIMMYT and Zimbabwe developed maize inbred lines under stress and optimal conditions. Euphytica 204:635-647

Nei M (1972) Genetic distance between populations. Am Nat 106:283-292

Rohlf JF (1998) NTSY-pc: numerical taxonomy and multivariate analysis system, version 2.1 Exdler software. New York: Setauket

Shamsuddin AK (1985) Genetic diversity in relation to heterosis and combining ability in spring wheat. Theor Appl Genet 70:306-308

Sincik M, Sozen E, Goksoy AT, Acikgoz E (2014) Heterosis and combining ability in a diallel cross of turnip rape genotypes. Turk J Field Crops 19:219-225

Smýkal P, Hýbl M, Corander J, Jarkovský J, Flavell AJ, Griga M (2008) Genetic diversity and population structure of pea (Pisum sativum L.) varieties derived from combined retrotransposon, microsatellite and morphological marker analysis. Theor Appl Genet 117:413-424

Su J, Zhang F, Li P, Guan Z, Fang W, Chen F (2016) Genetic variation and association mapping of waterlogging tolerance in chrysanthemum. Planta 244(6):1241-1252

Suwarno WB, Pixley KV, Palacios-Rojas N, Kaeppler SM, Babu R (2014) Formation of heterotic groups and understanding genetic effects in a provitamin A biofortified maize breeding program. Crop Sci 54:14-24

Tams SH, Bauer E, Oettler G, Melchinger AE, Schön CC (2006) Prospects for hybrid breeding in winter triticale: iI. Relationship between parental genetic distance and specific combining ability. Plant Breed 125:331-336

Tang QY, Feng MG (2002) DPS data processing system for practical statistics. Science and Publishing House, Beijing

Tarekegne AT (2001) Studies on genotypic variability and inheritance of waterlogging tolerance in wheat. PhD Dissertation, University of Free State, Bloemfontein, South Africa

Teixeira da Silva JA, Shinoyama H, Aida R, Matsushita Y, Raj SK, Chen F (2013) Chrysanthemum biotechnology: quo vadis? Crit Rev Plant Sci 32(1):21-52

Tiede T, Kumar L, Mohammadi M, Smith KP (2015) Predicting genetic variance in bi-parental breeding populations is more accurate when explicitly modeling the segregation of informative genomewide markers. Mol Breed 35:1-13

Wang C, Zhang F, Guan Z, Chen S, Jiang J, Fang W, Chen F (2014) Inheritance and molecular markers for aphid (Macrosiphoniella sanbourni) resistance in chrysanthemum (Chrysanthemum morifolium Ramat.). Sci Hortic 180:220-226

Weeden NF, Wendel JF (1989) Genetics of plant isozymes. In: Soltis D, Soltis P (eds) Isozymes in plant biology. Springer Verlag, Berlin, pp 46-72

Wegary D, Vivek B, Labuschagne M (2013) Association of parental genetic distance with heterosis and specific combining ability in quality protein maize. Euphytica 191:205-216

Yeboah MA, Chen XH, Liang GH, Gu MH, Xu CW (2008) Inheritance of waterlogging tolerance in cucumber $(\mathrm{Cu}$ cumis sativus L.). Euphytica 162:145-154 
Yin D, Chen S, Chen F, Guan Z, Fang W (2009a) Morphological and physiological responses of two chrysanthemum cultivars differing in their tolerance to waterlogging. Environ Exp Bot 67(1):87-93

Yin D, Guan Z, Chen S, Chen F (2009b) Establishment of evaluation system for waterlogging tolerance and identification of waterlogging tolerance in chrysanthemum morifolium and its related genera plants. J Plant Genet Res 10:399-404

Zaidi PH, Maniselvan P, Srivastava A, Yadav P, Singh RP (2010) Genetic analysis of water-logging tolerance in tropical maize (Zea mays L.). Maydica 55:17-26

Zhang F, Fang W, Chen F, Chen S (2010) Combining ability analysis on ornamental characters of chrysanthemum. Acta Hortic Sin 37:589-596
Zhang F, Chen S, Chen F, Fang W, Deng Y, Chang Q, Liu P (2011) Genetic analysis and associated SRAP markers for flowering traits of chrysanthemum (Chrysanthemum morifolium). Euphytica 177:15-24

Zhang F, Chen S, Jiang J, Guan Z, Fang W, Chen F (2013) Genetic mapping of quantitative trait loci underlying flowering time in chrysanthemum (Chrysanthemum morifolium). PLoS ONE 8:e83023

Zhou MX, Li HB, Mendham NJ (2007) Combining ability of waterlogging tolerance in barley. Crop Sci 47:278-284 